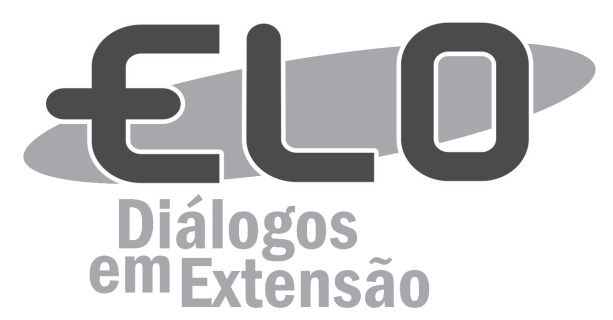

\title{
Reflexões sobre ações continuas de extensão e pesquisa em uma comunidade tradicional
}

\author{
Herton Helder Rocha Pires ${ }^{1}$, João Victor Leite Dias ${ }^{2}$, Nadja Maria Gomes Murta ${ }^{3}$
}

\begin{abstract}
Resumo: O presente relato apresenta reflexões sobre as ações desenvolvidas ao longo de oito anos (2008 2015) por Grupo de Extensão e Pesquisa da Universidade Federal dos Vales do Jequitinhonha e Mucuri em uma comunidade remanescente de quilombo do município de Diamantina, Minas Gerais. As atividades propostas permitiram o envolvimento direto da equipe no cotidiano da comunidade, sendo esse convívio reconhecido pelos moradores que, por sua vez, demonstraram confiança nos integrantes do Grupo e os acolheram como mais que puramente pesquisadores, antes como entes contribuintes para a comunidade. Essa relação de confiança brindou a equipe com a incumbência de organizar a festa dos padroeiros, honraria até então partilhada somente entre os moradores ou pessoas com ascendência local. Finalmente, discutiu-se a importância de um vínculo de longo prazo e o retorno das informações à comunidade em projetos de natureza extensionista.
\end{abstract}

Palavras-chave: Comunidades Quilombolas. Extensão Universitária. Relações Comunidade-Instituição.

Áreas Temáticas: Teorias e Metodologias em extensão; Ruralidade.

\section{Reflections about continuous activities of research and university extension in a traditional community}

Abstract: This report presents reflections about actions developed throughout eight years (2008 - 2015) by a University Extension and Research Team of the Universidade Federal dos Vales do Jequitinhonha e Mucuri in a 'quilombola' community in the municipality of Diamantina, Minas Gerais. The proposed activities allowed involvement of the team in the routine of the community, and it was recognized by the residents that demonstrated trust in the team members, not only as researchers, but as community contributors. These confidence relationship awarded the team with the responsibility in organize the local folk party, an honor restricted only to the residents or their relatives. Finally, the importance of a long-term bond together with feedback of information to the community by means of university extension proposals was discussed.

Keywords: Quilombolas Communities. University Extension. Community-Institutional Relations.

Thematic Areas: Theory and Methodologies in University extension; Rurality.

\section{Reflexiones sobre acciones continuas de extensión e investigación en una comunidad tradicional}

Resumen: Este informe presenta reflexiones sobre las acciones desarrolladas a lo largo de ocho años (2008 - 2015) por un Grupo de Extensión e Investigación de la Universidad Federal de los Valles del Jequitinhonha y Mucuri en una comunidad 'quilombola' de la municipalidad de Diamantina, Minas Gerais. Las actividades

\footnotetext{
${ }^{1}$ Professor - Universidade Federal dos Vales do Jequitinhonha e Mucuri, Grupo de Extensão e Pesquisa em Saúde Coletiva - JEQUI/CNPq, Programa de Pósgraduação em Saúde Sociedade e Ambiente -SaSA. Rua da Glória, 187, Centro, Diamantina - MG. E-mail: herton.pires@ufvjm.edu.br

2 Técnico-administrativo - Universidade Federal dos Vales do Jequitinhonha e Mucuri, Grupo de Extensão e Pesquisa em Saúde Coletiva - JEQUI/CNPq. E-mail: joao.dias@ufvjm.edu.br

${ }^{3}$ Professora - Universidade Federal dos Vales do Jequitinhonha e Mucuri, Grupo de Extensão e Pesquisa em Saúde Coletiva - JEQUI/CNPq, Programa de Pósgraduação em Saúde Sociedade e Ambiente -SaSA. E-mail: nadja.murta@ufvjm.edu.br
} 
propuestas permitieron el directo envolvimiento del equipo en el cotidiano de la comunidad, logrando el reconocimiento de los investigadores como parte activa en el desarrollo de la comunidad. Esta relación de confianza le dio al equipo la responsabilidad de organizar la fiesta de los patronos locales, un honor solamente compartido entre los moradores y sus familiares. Finalmente se discutió la importancia de un vínculo de largo plazo y también la retroalimentación de las informaciones para la comunidad en proyectos de extensión universitaria.

Palabras clave: Comunidades Quilombolas. Extensión Universitaria. Relaciones Comunidad-Institución. Área Temática: Teorías y Metodologías en extensión; Ruralidad.

\section{Apresentação}

O relato apresentado a seguir pretende descrever os desdobramentos advindos da execução de projetos de extensão e pesquisa realizados, entre os anos de 2008 a 2015, em uma comunidade remanescente de quilombo.

A comunidade de Quartel do Indaiá está localizada no município de Diamantina, Minas Gerais, na microbacia do Rio Caeté-Mirim, afluente da margem esquerda do Rio Jequitinhonha. A história oficial de Quartel do Indaiá está diretamente ligada à história da demarcação das áreas de extração de diamantes feita pela Fazenda Real portuguesa em 1734. Na atualidade os moradores mais velhos e também os mais jovens atribuem a origem e o nome da comunidade à presença de um Quartel que, por não ter telhas, era coberto por folhas de palmeiras de Indaiá, abundantes na área (MURTA, 2013).

No meio acadêmico, desde o final da década de 20 do século passado, a comunidade tem sido retratada por suas tradições e peculiaridades como, por exemplo, os cantos vissungos, que configuramse como cantigas presentes na vida cotidiana dos negros libertos e dos escravos: nos trabalhos realizados nas minas, no plantio de suas roças, no deslocamento de defuntos até o cemitério, na "encomenda" da alma, no aviso da chegada de estranhos, no levantamento dos mastros durante as festas religiosas e na dramaturgia (MACHADO-FILHO, 1985).

Atualmente residem na comunidade 25 famílias, resultando em uma população de cerca de 80 pessoas. As principais atividades de trabalho após o declínio do garimpo de diamantes são a pequena agricultura e a pecuária.

O primeiro contato do Grupo de Extensão e Pesquisa em Saúde Coletiva - Jequi/CNPq com a comunidade ocorreu no ano de 2008 quando um dos pesquisadores desse Grupo morou na comunidade para desenvolver parte da pesquisa da sua tese de doutorado, com foco na segurança alimentar e nutricional entre os moradores.

Desde então mais de 15 ações (extensão e pesquisa) foram desenvolvidas na comunidade, sendo abordadas diversas temáticas relacionadas aos direitos humanos, educação e saúde. Fundamental destacar que a maioria das ações foi de extensão, sendo fomentadas pela Pró-Reitoria de Extensão e Cultura da UFVJM.

Outro fato que merece destaque foi a aprovação, no ano de 2013, do projeto intitulado "Ação Participativa para a Promoção da Saúde e Controle de Doenças Parasitárias em Comunidade Tradicional" em edital da Fundação de Amparo à Pesquisa do Estado de Minas Gerais (FAPEMIG) na modalidade de projeto de Extensão em Interface com a Pesquisa, o que levou parte da equipe a manter um imóvel alugado (pago pelos pesquisadores com seus próprios recursos). Esse imóvel, além de servir como alojamento da equipe, armazenamento de materiais, local de desenvolvimento de ações educativas, proporcionou maior interação com a comunidade (Figura 1).

No transcorrer do período, conviveu-se com o cotidiano das famílias que residiam na comunidade: nascimentos, doenças, mortes, conflitos internos, lutas políticas, comemorações. $O$ fato de a equipe ter permanecido próxima da comunidade permitiu que o Grupo não fosse mais visto como "meros" pesquisadores. Os projetos de extensão eram vistos como tentativas de solução para os problemas por eles vividos. A presença contínua de alguns membros do Grupo Jequi, fez com que as principais lideranças da comunidade refletissem sobre a realização de projetos pontuais na comunidade. A título de exemplo citam-se as seguintes frases que relataram terem dito a respeito de outros grupos ou pesquisadores: "só as crianças andam com eles"; "eles vêm aqui, pegam a informação e nunca mais voltam"; "estamos cansados de tanta pergunta". 


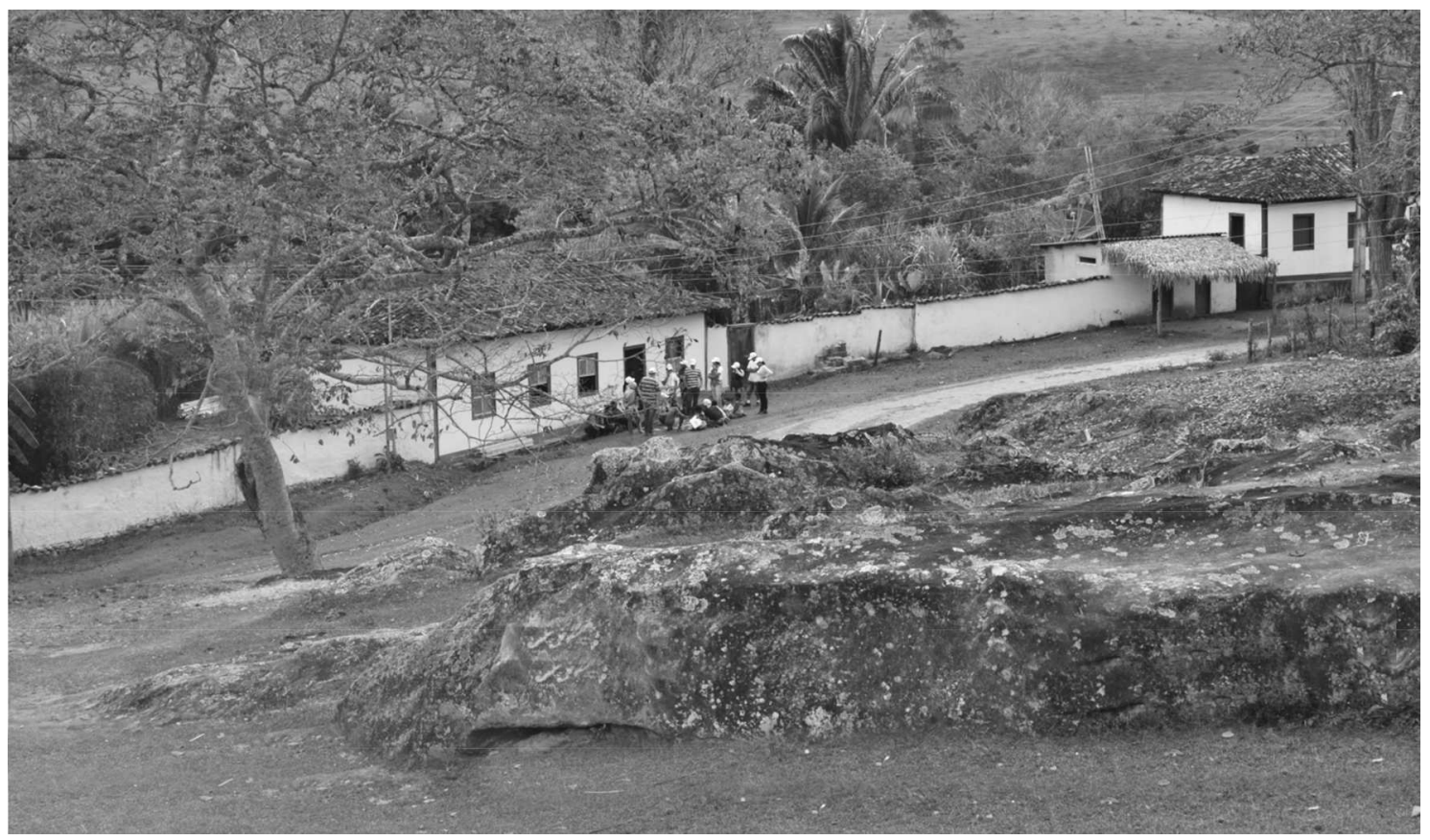

Figura 1 - Vista parcial da comunidade de Quartel do Indaiá, com a casa utilizada pelo Grupo de pesquisas Jequi ao centro. Julho de 2014.

Fonte: Arquivo pessoal de Dias, J. V. L.

Embora o Grupo estivesse ciente da confiança que lhe fora depositada, a constatação da estreita relação com a comunidade veio com o convite aos integrantes para participarem como festeiros da Festa de Nossa Senhora das Mercês e de São Vicente de Paulo, neste ano de 2015. Esse evento acontece anualmente durante o mês de julho, sendo o principal momento de encontro das famílias, parentes que não mais residem na comunidade e que aproveitam para reencontrar com seus familiares, bem como representa um encontro entre as comunidades vizinhas (Figura 2).

Esse convite promoveu no Grupo uma intensa reflexão sobre a forma como vinha atuando em Quartel do Indaiá. O que a diferenciava das ações executadas em outros locais?

Ao se avaliar a questão, concluiu-se que, embora inicialmente não fosse a intenção de o Grupo atuar na comunidade de forma contínua, o envolvimento afetivo com a comunidade mudou o ritmo das vidas dos integrantes do Grupo. Nesse intervalo de tempo os projetos de extensão nasciam da real observação dos problemas da comunidade, fugindo daqueles que, em geral, nascem exclusivamente dentro dos espaços acadêmicos, muitas vezes baseados em informações e dados coletados em ações verticalizadas ou programáticas do governo ou outras instituições.

Por outro lado, a própria comunidade passou a questionar determinados tipos de projetos e a nós como Grupo ou individualmente, atribuindo, ao mesmo tempo, responsabilidade e honrarias. Nesse sentido, a presença perene na comunidade possibilitou ao Grupo a tomada das decisões a respeito da condução das ações de forma integrada com a população e ainda oportunizou a devolução de informações coletadas durante as diversas pesquisas, seja por meio de apresentações em eventos coletivos ou individualmente em conversas com moradores.

Ante o exposto, acrescenta-se a constatação da importância de que atividades de cunho extensionista efetivamente colaborem com a comunidade na tomada das decisões, sobretudo no que diz respeito à detecção e ao enfrentamento de suas próprias problemáticas. Nesse sentido, Dias (1998) destaca a necessidade de uma reorientação nas relações entre a academia e a comunidade, não olvidando a reciprocidade existente nessa relação que envolve a "escuta" e a auto-reflexão o que, segundo a autora, endossa a confiança e contribui para o alcance de resultados mais efetivos e duradouros.

Finalmente, este relato remete, ainda, aos pressupostos da Política Nacional de Extensão Universitária (FORPROEX, 2012), na medida em que apresenta uma experiência fundamentada na relação dialógica de caráter longitudinal como forma de compreender e apoiar a solução de demandas concretas de uma comunidade. 


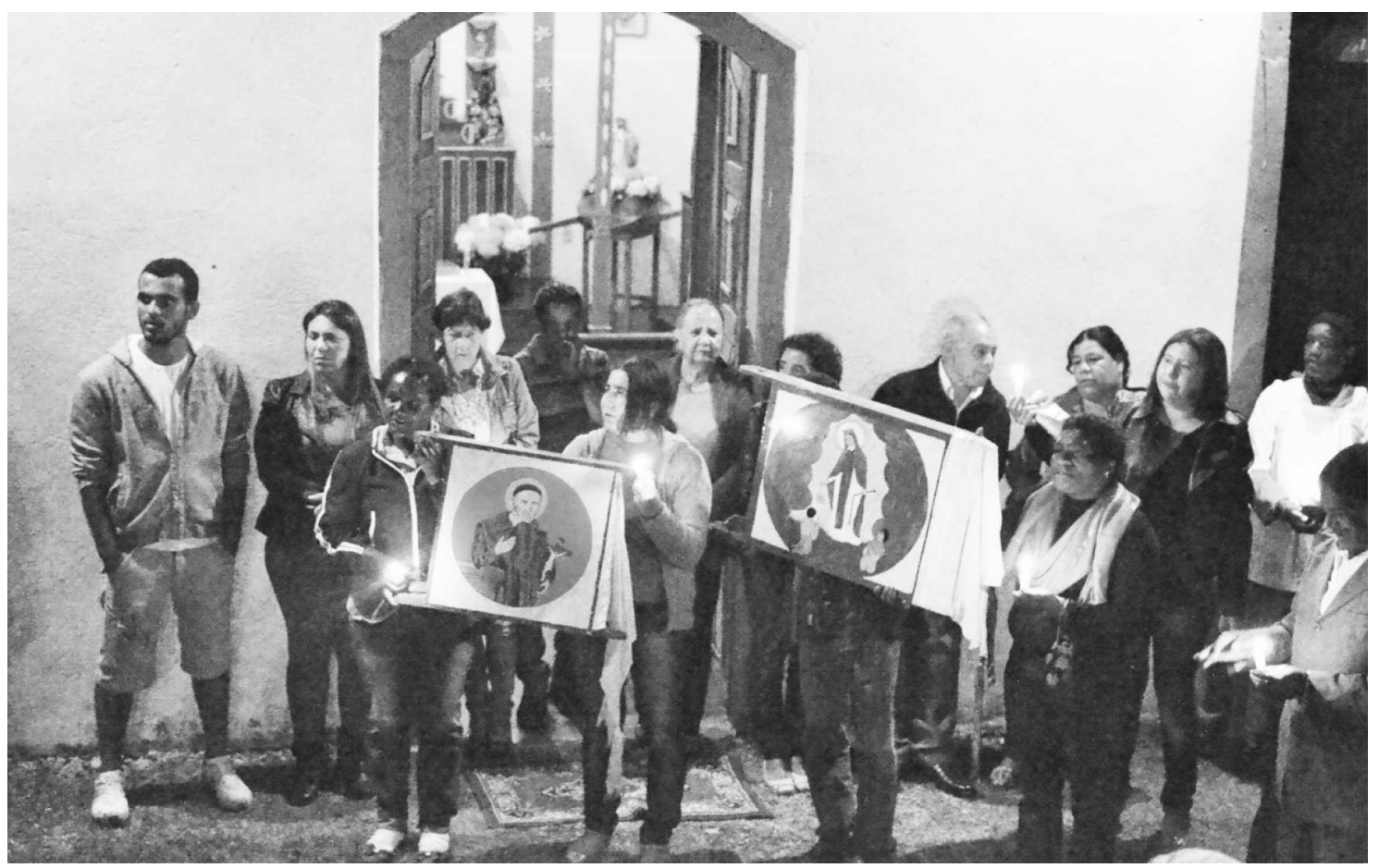

Figura 2 - Saída da procissão na Festa de Nossa Senhora das Mercês e São Vicente de Paulo na comunidade de Quartel do Indaiá. Julho de 2014.

Fonte: Arquivo pessoal de Dias, J. V. L.

\section{Referências bibliográficas}

DIAS, R.B. “Eu? Eu estou aí, compondo o mundo." Uma experiência de controle de endemia, pesquisa e participação popular vivida em Cansanção, Minas Gerais, Brasil. Cadernos de Saúde Pública, v. 14, Sup. 2, p. 149-157, 1998.

FORPROEX. Fórum de Pró-Reitores de Extensão das Universidades Públicas Brasileiras. Política Nacional de Extensão Universitária. Manaus, 2012. 40 p.

MACHADO-FILHO, A.M. O negro e o garimpo em Minas Gerais. Belo Horizonte: Itatiaia; São Paulo: EDUSP, 1985. 144 p.

MURTA, N.M.G. O acaso dos casos: estudos sobre alimentação-nutrição, cultura e história. [Tese de doutorado]. Programa de Estudos Pós-graduados em Ciências Sociais. Pontifícia Universidade Católica de São Paulo. São Paulo. 2013. 172 f. 